\title{
Cloning and Chromosomal Localization of a Human Kidney CDNA Involved in Cystine, Dibasic, and Neutral Amino Acid Transport
}

\author{
Wen-Sen Lee, Rebecca G. Wells, Rachel V. Sabbag, T. K. Mohandas, " and Matthias A. Hediger \\ Renal Division, Department of Medicine, Brigham and Women's Hospital and Harvard Medical School, and the Harvard Center for the \\ Study of Kidney Diseases, Boston, Massachusetts 02115; and *Division of Medical Genetics, Harbor-University of California Los \\ Angeles Medical Center, Torrance, California 90509
}

\begin{abstract}
We have recently cloned, sequenced, and characterized a rat kidney cDNA (D2) that stimulates cystine as well as dibasic and neutral amino acid transport. In order to evaluate the role of this protein in human inherited diseases such as cystinuria, we have isolated a human D2 clone (D2H) by low stringency screening of a human kidney cDNA library using the radiolabeled D2 insert as a probe. The D2H cDNA is 2284 nucleotides long and encodes a 663 amino acid protein that is $80 \%$ identical to the rat $\mathrm{D} 2$ amino acid sequence and $86 \%$ to that of the rabbit homologue rBAT. Microinjection of in vitro transcribed D2H cRNA into Xenopus oocytes induced uptake of cystine as well as dibasic and neutral amino acids in a pattern similar to that of rat D2 and rabbit rBAT. Both neutral and dibasic amino acids inhibited the D2H-induced uptake of cystine. Northern blot analysis demonstrated that D2H, like D2 and rBAT, is expressed strongly in the kidney and intestine. Southern blot analysis of genomic DNA from a panel of mouse-human somatic cell hybrids showed that the human gene for D2H resides on chromosome 2. (J. Clin. Invest. 1993. 91:1959-1963.) Key words: amino acid transporter • cystinuria • Hartnup disorder • chromosome $2 \cdot$ high affinity transport
\end{abstract}

\section{Introduction}

Absorption of amino acids in the kidney and small intestine is believed to be mediated by transporters with well-defined specificities, although little is known about these proteins at the molecular level. Cloning by expression in Xenopus oocytes has resulted in the isolation of the kidney and intestine-specific DNA clones: rat D2 (1), rat NAA-Tr (2) and rabbit rBAT (3). D2 and rBAT, which have $82 \%$ amino acid sequence identity, induce the high affinity uptake into oocytes of a previously unreported broad spectrum of amino acids, including cystine, dibasic, and neutral amino acids. NAA-Tr, which has an identical coding sequence to $D 2$, has been reported to have a different spectrum of uptake. These proteins, unlike most known transporters, are type II membrane glycoproteins. They have a low but significant degree of similarity to $\alpha$-glucosidases and to

Address correspondence and reprint requests to Dr. Matthias A. Hediger, Renal Division, Brigham and Women's Hospital, 75 Francis Street, Boston, MA 02115. Dr. Wells' present address is The Whitehead Institute for Biomedical Research, 9 Cambridge Center, Cambridge, MA 02142 .

Received for publication 30 September 1992 and in revised form 3 December 1992.

J. Clin. Invest.

(c) The American Society for Clinical Investigation, Inc.

$0021-9738 / 93 / 05 / 1959 / 05 \quad \$ 2.00$

Volume 91, May 1993, 1959-1963 the $4 \mathrm{~F} 2$ cell surface antigen heavy chain. cRNA from $4 \mathrm{~F} 2$ also induces amino acid uptake into oocytes, although with a different substrate specificity $(1,4,5)$, leading to the suggestion that D2, rBAT, and the 4F2 heavy chain are not transporters but instead comprise a family of transport regulators or regulatory subunits of heterooligomeric transporters $(1,3,4)$.

In our investigations of the function of D2 and the related proteins, a significant question concerns their role in in vivo amino acid transport, both in normal tissues and, potentially, in human inherited disorders of transport such as cystinuria and Hartnup disorder. Cystinuria is a disorder in which transport of cystine, lysine, arginine, and ornithine is impaired, whereas Hartnup disorder is characterized by impaired neutral amino acid transport excluding the imino acids and glycine (6, $7)$. In order to evaluate the role of D2 in normal and abnormal amino acid transport, we used a rat $\mathrm{D} 2$ probe to isolate a D2like cDNA (D2H) from a human kidney library. We present functional data showing that $\mathrm{D} 2 \mathrm{H}$, like D2, induces the uptake of a broad spectrum of amino acids into oocytes. In addition, we map D2H to human chromosome 2 .

\section{Methods}

Library screening. The human clone was isolated from a human kidney library in phage $\lambda$ GT 10, kindly provided by Graeme Bell, University of Chicago (8). Phage were transfected into VCS257 cells, plated, and transferred onto nitrocellulose filters (Schleicher \& Schuell, Inc., Keene, NH). A ${ }^{32} \mathrm{P}$-labeled probe was prepared from the Sacl fragment of the D2 rat kidney cDNA ( ${ }^{\mathrm{T} 7}$ Quick Prime Kit; Pharmacia Fine Chemicals, Piscataway, NJ). Filters were hybridized with the probe overnight $\left(45^{\circ} \mathrm{C}\right.$ in a $50 \%$ formamide hybridization mix) and washed at low stringency in $0.1 \times \operatorname{SSC}(3 \mathrm{M}$ sodium chloride, $0.3 \mathrm{M}$ sodium citrate, $\mathrm{pH} 7.0) / 0.1 \%$ SDS at $45^{\circ} \mathrm{C}$. There were approximately 40 strongly positive plaques out of 150,000 screened. Of these, 6 were plaque purified. Phage DNA was then isolated (Lambdasorb; Promega Biotec, Madison, WI) and cut with EcoRI to remove inserts. Inserts were gel purified (Geneclean; Bio 101, Inc., Vista, CA) and subcloned into pBluescriptII (Stratagene, La Jolla, CA). Two clones were selected for $5^{\prime}$ and 3 ' end sequencing: One clone, referred to as D2H, showed significant sequence similarity to clone D2 and was used for all further analyses.

Sequencing of the cDNA clone. D2H cDNA was subcloned using fragments produced by internal restriction sites. Both strands of the clone were sequenced in their entirety using a ${ }^{\mathrm{T}}$ polymerase didoxy sequencing kit (Pharmacia Fine Chemicals); synthetic oligonucleotide primers were used to complete sequencing. Sequence analysis and alignment were performed using the software described before (9).

RNA preparation and northern-blot analysis. Poly $(\mathrm{A})^{+} \mathrm{RNA}$ from the human kidney (provided by Jill Norman, UCLA, School of Medicine) or ileum (provided by M. Stelzner and E. W. Fonkalsrud, UCLA) was prepared by the guanidinium isothiocyanate method using cesiumtrifluoroacetic acid as described by the manufacturer (Pharmacia Fine Chemicals). RNA ( $2.5 \mu \mathrm{g}$ per lane) was electrophoresed on a $1 \%$ formaldehyde agarose gel and blotted onto a nitrocellulose filter. The D2H 
insert was excised from pBluescript using EcoRI and labeled with the ${ }^{\mathrm{T} 7}$ QuickPrime kit. Filters were hybridized at $37^{\circ} \mathrm{C}$ for $18 \mathrm{~h}$ using a $50 \%$ formamide hybridization mix and then washed in $0.1 \times \mathrm{SSC} / 0.1 \%$ SDS at $50^{\circ} \mathrm{C}$.

In vitro transcription and functional characterization. In vitro transcription of $\mathrm{D} 2 \mathrm{H}$ was performed according to a modification of the methods of Krieg and Melton (10). Collagenase-treated and manually defolliculated Xenopus oocytes were injected with $50 \mathrm{nl}$ of water (control group) or D2H cRNA (generally 40-50 ng) as described (11) and were maintained in $\mathrm{ND} 96$ solution $(96 \mathrm{mM} \mathrm{NaCl}, 2 \mathrm{mM} \mathrm{KCl}, 1.8 \mathrm{mM}$ $\mathrm{CaCl}_{2}, 1 \mathrm{mM} \mathrm{MgCl}, 5 \mathrm{mM}$ Hepes, $\mathrm{pH} 7.4$ ) supplemented with 2.5 $\mathrm{mM}$ pyruvate and $50 \mathrm{mg} / \mathrm{ml}$ gentamicin. $3 \mathrm{~d}$ after injection, oocytes were incubated in groups of six to eight for $1 \mathrm{~h}$ in $0.75 \mathrm{ml}$ uptake solution containing $1.0 \mu \mathrm{Ci}$ of the radiolabeled substrate and $100 \mathrm{mM}$ $\mathrm{Na}^{+}$or, in the case of $\mathrm{Na}^{+}$-free incubations, $100 \mathrm{mM} \mathrm{N}$-methyl-D-glucosamine (NMDG). Unlabeled amino acids were added to the incubation mixture where necessary to bring the total amino acid concentration to $15 \mu \mathrm{M}$ (or to the concentrations specified for $K_{\mathrm{m}}$ determinations). For each inhibition experiment, an additional unlabeled amino acid was added to a final concentration of $2 \mathrm{mM}(0.5 \mathrm{mM}$ for cystine, which is poorly soluble in water). Uptakes were stopped by washing each group of oocytes four to five times with ice-cold $\mathrm{Na}^{+}$-free uptake solution. Individual oocytes were solubilized in $250 \mu \mathrm{l}$ of $10 \%$ SDS and counted. Each data point represents the mean of uptake into six to eight oocytes.

Chromosome mapping. The chromosomal localization of the D2H gene was performed using genomic DNA from human-mouse and human-hamster hybrids as previously described $(12,13)$. DNA $(10$ $\mu \mathrm{g} /$ lane ) was digested with EcoRI, separated on a $0.8 \%$ agarose gel, and transferred onto a nitrocellulose membrane (Zetabind; Cuno, Inc., Meriden, CT). The EcoRI fragment of D2H was gel-purified and ${ }^{32} \mathrm{P}$ labeled ( ${ }^{\mathrm{T}} \mathrm{Q}$ Quick Prime Kit) for use as a probe. The filter was hybridized at $37^{\circ} \mathrm{C}$ for $18 \mathrm{~h}$ in a $50 \%$ formamide hybridization mix and was washed at high-stringency in $0.1 \times \mathrm{SSC}$ and $0.1 \% \mathrm{SDS}$ at $65^{\circ} \mathrm{C}$.

\section{Results and Discussion}

Low stringency screening of a human kidney cDNA library with rat $\mathrm{D} 2$ as a probe has resulted in the isolation of a clone, D2H, which shows significant sequence similarity to clones D2 $(1,2)$ and rBAT $(3)$. This clone is 2284 nucleotides long and contains an open reading frame from residues 45 to 2036 with an initial methionine. It predicts a 663 amino acid protein with $80 \%$ identity to the rat $\mathrm{D} 2$ protein and $86 \%$ identity to the rabbit rBAT protein (Fig. 1). Like the D2 and rBAT proteins, the protein predicted by $\mathrm{D} 2 \mathrm{H}$ encodes a type II membrane glycoprotein with only one putative transmembrane domain, a structure unlike most other cloned transporters which have multiple membrane-spanning regions $(11,14-16)$. Sequence conservation extends across all three regions of the protein (cytoplasmic $\mathrm{NH}_{2}$ terminus, transmembrane region, and extracellular $\mathrm{COOH}$ terminus). We have previously suggested that the

1

HUMAN(D2H) MAEDKSKRDS IEMSMKGCQT NNGFVHNEDI LEQTPDPGSS TDNLKHSTRG ILGSQEPDFK GVQPYAGMPK EVLFQFSGQA RYRIPREILF WLTVASVLVL

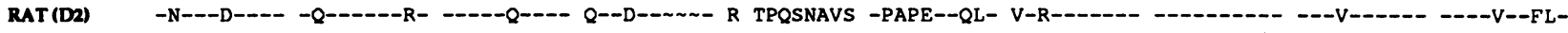
RABBIT (rBAT) ---EG---D -K-N---D -

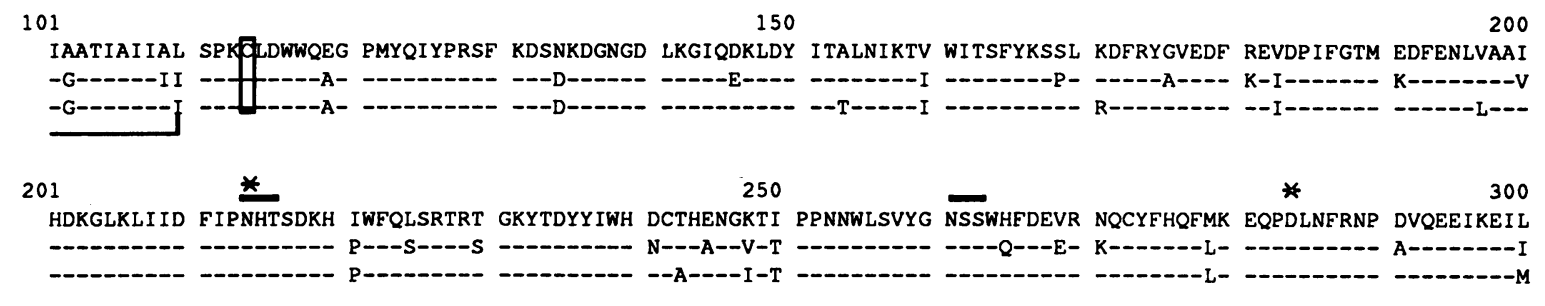

$301 \quad 350$ RFWLTKGVDG FSLDAVKFLL EAKHLRDEIQ VNKTQIPDTV TQYSELYHDF TTTQVGMHDI VRSFRQTMDQ YSTEPGRYRF MGTEAYAESI DRTVMYYGLP K--S$401 \quad 450 \quad 500$ FIQEADFPFN NYLSMLDTVS GNSVYEVITS WMENMPEGKW PNWMIGGPDS SRLTSRLGNQ YVNVMNMLLF TLPGTPITYY GEEIGMGNIV AANLNESYDI -

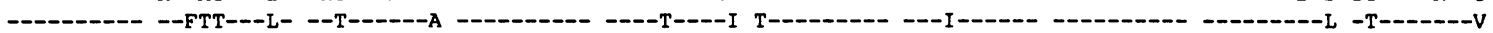

501 $12550 \quad 600$ -A-L--- - -

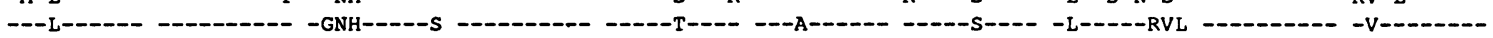

601 650

E STLLNLHN MISGLPAKIR IRLSTNSADK GSKVDTSGIF LDKGEGLIFE HNTKNLLHRQ TAFR

-S--V---QE T--DV-T-L- ------P-S- --D---HAVS -E------L- -SM-T---H- K---DKCFIS NRACYSSVLD LLYSSC

$-----Q E$----VRLS -K-----ST --Q---R--- -ER---VLL- -KM------ ----DRCFIS SRACYSSALD ILYSSC

Figure 1. Alignment of the amino acid sequences of D2H, D2, and rBAT. The amino acid sequence of D2H is aligned with the D2 (rat) and rBAT (rabbit). For the amino acid sequences of D2 and rBAT, only those residues that are different from $\mathrm{D} 2 \mathrm{H}$ are shown. The single predicted transmembrane region $(T M)$ and the leucine zipper motif $(L Z)$ are indicated. The conserved cysteine residue (indicated by box) has been suggested to be associated to a second subunit. Asn-214 and Asp-284 correspond to the proposed calcium-binding ligands Asn-100 and Asp-167 in porcine pancreatic amylase (17). Six potential N-linked glycosylation sites (consensus NXS/T) are marked by bold lines. (The DNA sequence of clone D2H has been deposited in the Genbank database with accession number M95548.) 
D2 and rBAT proteins might undergo dimerization mediated by leucine zippers (1). A leucine zipper motif is found in D2H at an almost identical position as in D2 and rBAT except that the last leucine is substituted by histidine. In the 4F2 heavy chain, a cysteine residue located just $\mathrm{COOH}$-terminal to the transmembrane region may be involved in a disulfide linkage to the 4F2 light chain (4). This residue is conserved in $\mathrm{D} 2 \mathrm{H}$, D2, and rBAT (cysteine 114), suggesting another potential mechanism for oligomerization. In D2H, Asn-214 and Asp284 correspond to the proposed calcium-binding ligands Asn100 and Asp-167 in porcine pancreatic amylase (17). The human, rat, and rabbit sequences are the least conserved near the $\mathrm{COOH}$ terminus. The $\mathrm{COOH}$-terminal 22 amino acids present and highly conserved in the D2 and rBAT proteins are missing in the D2H protein. D2H has six predicted $\mathrm{NH}_{2}$-glycosylation sites, four in common with D2 and rBAT.

D2H, like D2 and rBAT $(1,3)$, induces the uptake of cystine as well as neutral and dibasic amino acids when in vitro transcribed and injected into oocytes (Fig. 2). The $K_{\mathrm{m}}$ values for cystine uptake are $30 \mu \mathrm{M}$ for D2H (Fig. 3), $67 \mu \mathrm{M}$ for rat $\mathrm{D} 2$ and $36 \mu \mathrm{M}$ for rabbit rBAT. These values are within the range characteristic of high affinity cystine transport. Uptake of radiolabeled cystine is inhibited by an excess of unlabeled lysine or leucine. Likewise, uptake of the neutral amino acid leucine is inhibited by an excess of cystine or lysine (Fig. 4). This pattern of inhibition suggests that $\mathrm{D} 2 \mathrm{H}$-induced amino acid uptake, like D2-induced uptake, represents activation of a single transport system $(1,3)$. Our experiments demonstrated that the uptake of $\left[{ }^{14} \mathrm{C}\right] \mathrm{L}$-alanine or $\left[{ }^{14} \mathrm{C}\right] \mathrm{L}$-serine in oocytes injected with D2H cRNA is mostly ( $>80 \%$ ) $\mathrm{Na}^{+}$-independent (data not shown). This is in accord with oocyte expression studies of rat D2 (1).

Northern blot analysis demonstrates that D2H, like D2 and rBAT, is located in the kidney and intestine. After hybridiza-

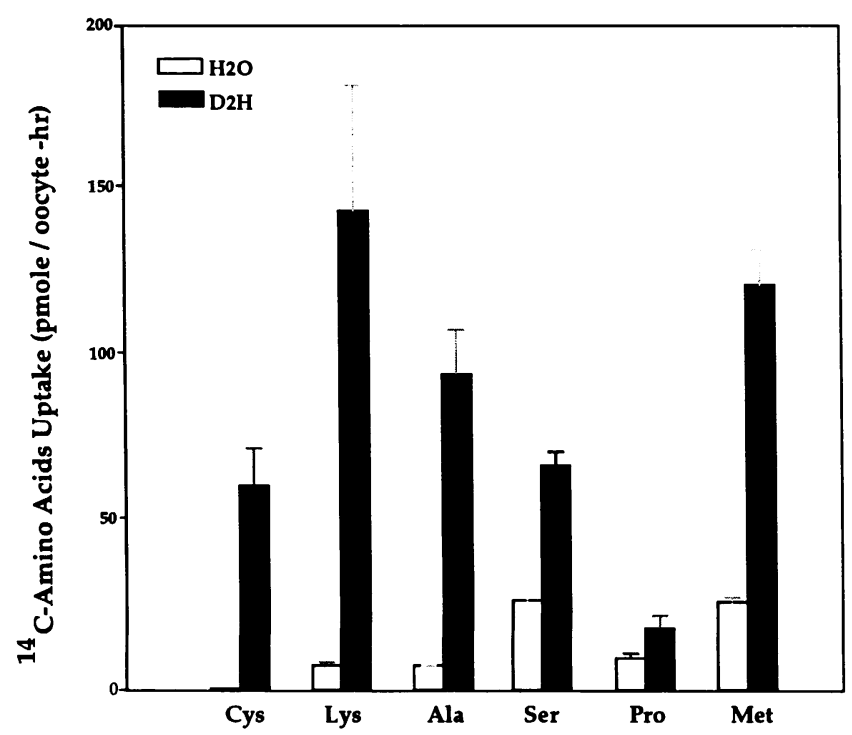

Figure 2. D2H cRNA induces amino acid uptake into oocytes. Oocytes injected with water (open columns) or with D2H-cRNA ( solid columns) were assayed $3 \mathrm{~d}$ after injection. The uptake of $15 \mu \mathrm{M}$ radiolabeled amino acids was determined during $1-\mathrm{h}$ incubations in the presence of $100 \mathrm{mM} \mathrm{Na}^{+}$. The columns represent the mean \pm SEM obtained from six to eight oocytes per group. Cys, cystine; Lys, lysine; Ala, alanine; Ser, serine; Pro, proline; Met, methionine.

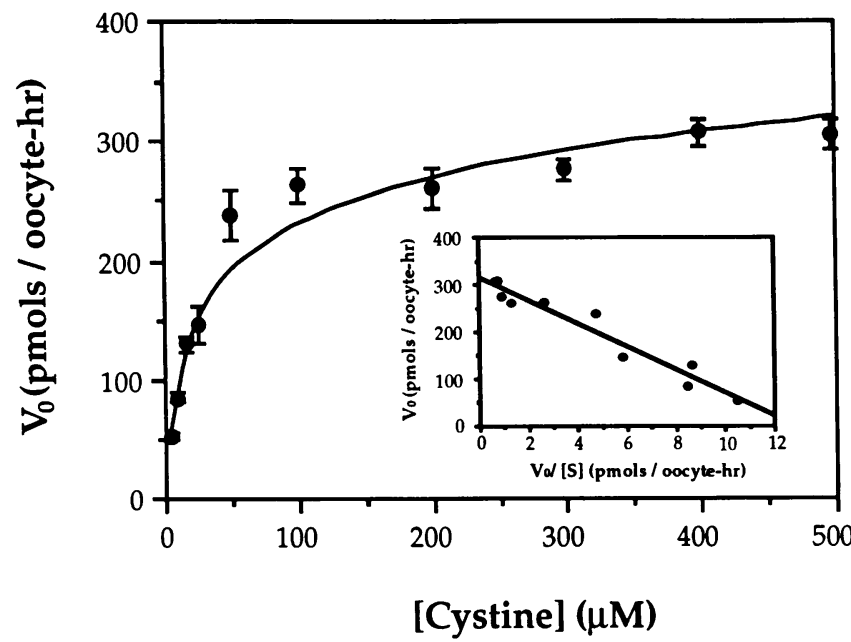

Figure 3. D2H-induced uptake of cystine is saturable. Oocytes injected with water or with D2H cRNA were assayed three days after injection for uptake of radiolabeled L-cystine at concentrations ranging from 5 to $497 \mu \mathrm{M}$. D2H-induced uptakes (subtract from waterinjected values) were used for the Michaelis-Menton (main figure) and Eadie-Hofstee (inset) plots shown. $K_{\mathrm{m}}$ and $V_{\max }$ values for D2H were calculated from Eadie-Hofstee equation. $K_{\mathrm{m}}=30 \mu \mathrm{M} . V_{\max }$ $=319 \mu \mathrm{M}$.

tion with a labeled $\mathrm{D} 2 \mathrm{H}$ fragment, a strong signal at $2.3 \mathrm{~kb}$ and a weak signal of $4.3 \mathrm{~kb}$ were seen for mRNA from human kidney and intestine (Fig. 5). The 2.3-kb signal represents the message size expected for the cDNA clone. The $4.3 \mathrm{~kb}$ signal may result from the use of a different polyadenylation site. We have not yet studied the cellular distribution of $\mathrm{D} 2 \mathrm{H}$, but have

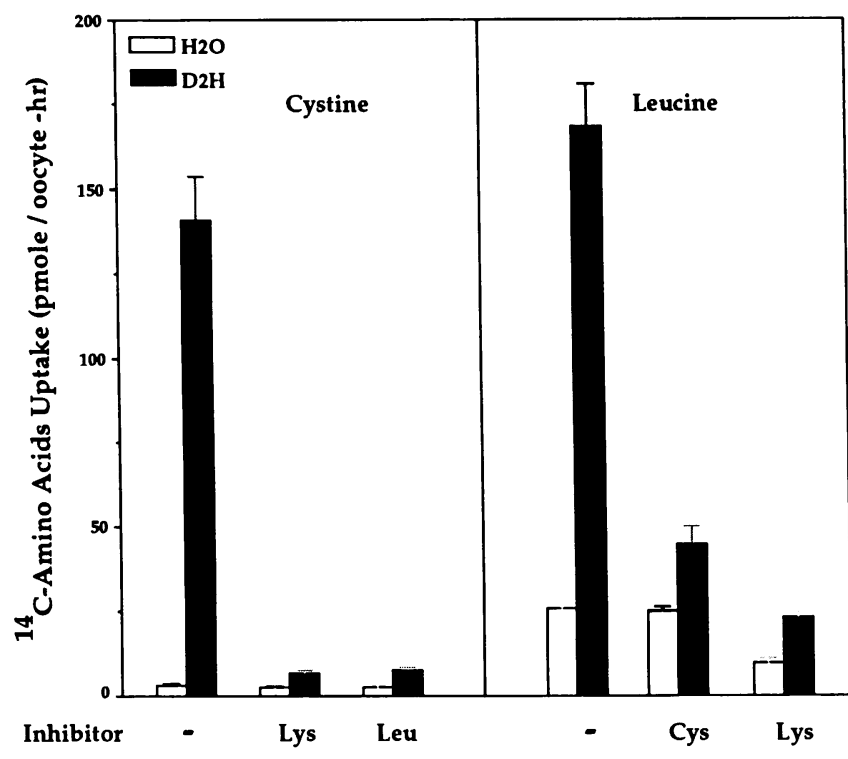

Figure 4. D2H-induced uptake of radiolabeled L-cystine and L-leucine is inhibited by an excess of unlabeled neutral and dibasic amino acids. Oocytes injected with water or D2H cRNA were assayed three days after injection for uptake of $15 \mu \mathrm{M}{ }^{14} \mathrm{C}$-labeled L-cystine (left) or L-leucine (right) alone and in the presence of $2 \mathrm{mM}(0.5 \mathrm{mM}$ for Lcystine) of an unlabeled amino acid as indicated. Uptake was performed in the presence of $100 \mathrm{mM} \mathrm{Na}^{+}$. The columns represent the mean \pm SEM obtained from six to eight oocytes per group. Lys, lysine; Leu, leucine. 


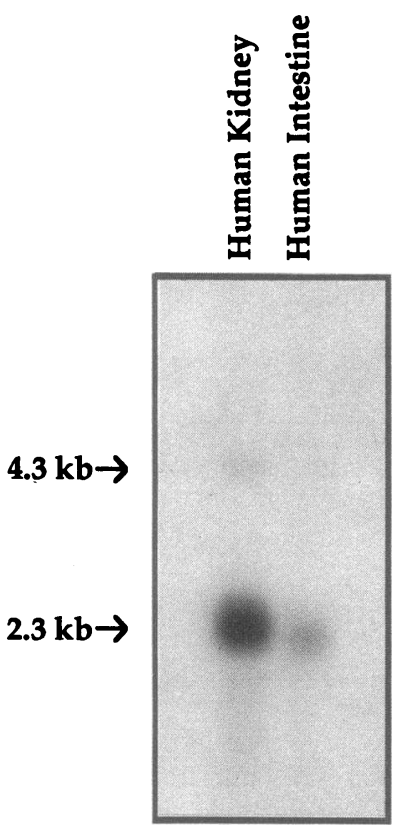

Figure 5. Northern blot analysis of human kidney and ileum mRNA. The blot was probed with ${ }^{32} \mathrm{P}$-labeled D2H-cDNA. Prehybridization and hybridization were done at $37^{\circ} \mathrm{C}$. Filters were then washed in $0.1 \times \mathrm{SSC} / 0.1 \% \mathrm{SDS}$ at $50^{\circ} \mathrm{C}$.

previously demonstrated by in situ hybridization that $\mathrm{D} 2$ from rat is expressed specifically in the proximal tubule $\mathbf{S} 3$ segment of the rat kidney outer medulla, a region of high affinity brush border amino acid transport (18). This localization is consistent with in vitro microperfusion studies of proximal tubule segments using rabbit (19) and rat kidney (20), which demonstrated that high affinity transport of cystine occurs in the proximal straight tubule.

Although D2 and D2H induce the uptake of cystine as well as dibasic and neutral amino acids into Xenopus oocytes up to
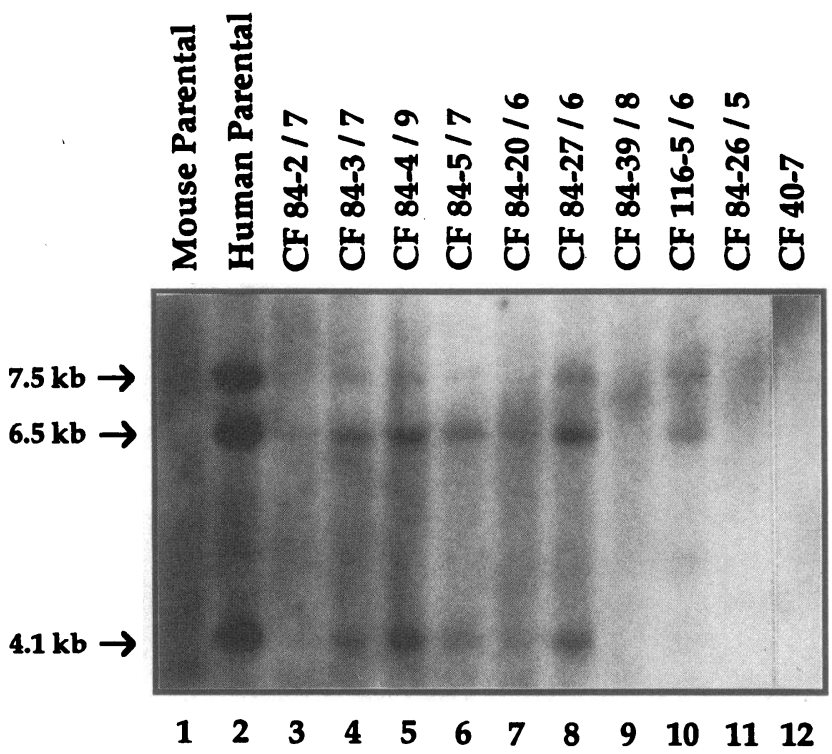

Figure 6. Southern blot analysis of rodent-human somatic cell hybrids for the presence of the human D2 gene. The DNA was digested with EcoRI. Lanes 1 and 2 contain DNA from mouse and human parental cells, respectively; lanes 3-12 contain DNA from mousehuman hybrid clones. The filter was probed with the D2H cDNA and then washed under high-stringency conditions. Strong hybridization to the D2H-specific bands $(4.1,6.5$, and $7.5 \mathrm{~kb})$ is seen in lanes $2,4,5,6,8$, and 10 ; weak hybridization is seen in bands 3 , and 7 .

$150-400$-fold, the function of these proteins is not clearly understood. We have suggested that D2 may represent a transport regulator or regulatory subunit of a heterodimeric transporter $(1,3,5)$. The potential role of the D2 protein in human inherited diseases of amino acid transport, such as cystinuria and Hartnup disorder, is intriguing. D2 and D2H exhibit $K_{\mathrm{m}}$ values for cystine and dibasic amino acids, and tissue specific expression similar to those previously described for the transporter predicted to be defective in cystinuria $(6,19,21)$. If the potential compensation for neutral amino acid uptake from multiple other amino acid transporters (e.g., system L) is taken into account, then a defect in the D2 protein could explain the impaired cystine and dibasic amino acid excretion seen in cystinuria (22). Previous results from hybrid-depletion experiments, (i.e., incubation of kidney poly (A) ${ }^{+}$RNA with a D2 antisense oligonucleotide) resulted in the elimination of the majority of cystine uptake induced by kidney mRNA in Xenopus oocytes. This suggests that the D2 protein is an integral part of cystine uptake in the kidney, which is consistent with it playing a role in cystinuria.

As a preliminary step toward evaluating the possible genetic linkage between the human D2 gene and these disease states, we have mapped D2H to human chromosome 2. Fig. 6 shows that genomic DNA from human-mouse hybrids, when cut with EcoRI and hybridized at high stringency with a radiolabeled probe from D2H cDNA, resulted in three major bands at

Table I. Segregation of D2H with Human Chromosomes in Cell Hybrids

\begin{tabular}{|c|c|c|c|c|c|}
\hline \multirow[t]{2}{*}{$\begin{array}{c}\text { Human } \\
\text { chromosome }\end{array}$} & \multicolumn{4}{|c|}{ Number of clones } & \multirow{2}{*}{$\frac{\text { Discordancy }}{\%}$} \\
\hline & $+/+^{*}$ & $+/-$ & $-1+$ & $-1-$ & \\
\hline 1 & 4 & 3 & 1 & 7 & 27 \\
\hline 2 & 7 & 0 & 0 & 8 & 0 \\
\hline 3 & 5 & 2 & 4 & 4 & 40 \\
\hline 4 & 5 & 2 & 6 & 2 & 53 \\
\hline 5 & 5 & 2 & 3 & 5 & 33 \\
\hline 6 & 6 & 1 & 6 & 2 & 47 \\
\hline 7 & 4 & 3 & 7 & 1 & 67 \\
\hline 8 & 7 & 0 & 7 & 1 & 47 \\
\hline 9 & 0 & 7 & 1 & 7 & 53 \\
\hline 10 & 3 & 4 & 3 & 5 & 47 \\
\hline 11 & 3 & 4 & 4 & 4 & 53 \\
\hline 12 & 4 & 3 & 5 & 3 & 53 \\
\hline 13 & 4 & 3 & 1 & 7 & 27 \\
\hline 14 & 5 & 2 & 5 & 3 & 47 \\
\hline 15 & 7 & 0 & 3 & 5 & 20 \\
\hline 16 & 3 & 4 & 2 & 6 & 40 \\
\hline 17 & 6 & 1 & 7 & 1 & 53 \\
\hline 18 & 6 & 1 & 2 & 6 & 20 \\
\hline 19 & 5 & 2 & 4 & 4 & 40 \\
\hline 20 & 6 & 1 & 4 & 4 & 33 \\
\hline 21 & 4 & 3 & 3 & 5 & 40 \\
\hline 22 & 4 & 3 & 3 & 5 & 40 \\
\hline$X$ & 3 & 4 & 1 & 7 & 33 \\
\hline $\mathbf{Y}$ & 1 & 6 & 1 & 7 & 47 \\
\hline
\end{tabular}

* +/+, D2H present/chromosome present; +/-, D2H present/chromosome absent; -/+, D2H absent/chromosome present; -/-, D2H absent/chromosome absent. 
$4.1,6.5$, and $7.5 \mathrm{~kb}$. There was no hybridization to bands of these sizes in mouse (Fig. 6) or hamster (data not shown) genomic DNA. Strong hybridization to the D2H-specific bands is seen in clones 84-3, 84-4, 84-5, 84-27, and 116-5; weak hybridization is seen in clones 84-2 and 84-20. Correlation of the hybridization pattern with the human chromosome content of a panel of 15 somatic cell hybrids showed that the D2H gene residues on human chromosome 2 (Table I). There was no discordancy for human chromosome 2 , while the discordancy rate for every other human chromosome was $20 \%$ or more. The weak hybridization signal seen in clones $84-2$ and $84-20$ was consistent with the low level of retention of chromosome 2 in these two clones. One of the hybrid clones analyzed (CF 40-7) retained an $\mathrm{X} / 2$ translocation chromosome containing q32.3 $\rightarrow$ qter region of human chromosome 2 (23). This clone was negative for the presence of D2H (Fig. 6), indicating that the D2H locus is in the pter $\rightarrow \mathrm{q} 32.3$ region of chromosome 2 .

In conclusion, we have cloned, sequenced, and characterized a human D2 cDNA. The sequence of this clone is highly similar at the amino acid level to that of D2 from rat, and has a similar tissue distribution and functional characteristics. $\mathrm{D} 2 \mathrm{H}$ will facilitate studies into the potential role of members of the D2 family in normal and abnormal amino acid transport.

\section{Acknowledgments}

We would like to acknowledge the technical assistance of Ms. P. Boutin.

This research was supported by a National Institutes of Health grant (DK-43171) to M. A. Hediger and by a Juvenile Diabetes Foundation International grant to W-S. Lee. R. G. Wells is a Howard Hughes Medical Institute Physician Research Fellow.

\section{References}

1. Wells, R. G., and M. A. Hediger. 1992. Cloning of a rat kidney cDNA that stimulates dibasic and neutral amino acid transport and has sequence similarity to glucosidases. Proc. Natl. Acad. Sci. USA. 89:5596-5600.

2. Tate, S. S., N. Yan, and S. Udenfriend. 1992. Expression cloning of a $\mathrm{Na}^{+}$-independent neutral amino acid transporter from rat kidney. Proc. Natl. Acad. Sci. USA. 89:1-5.

3. Bertran, J., A. Werner, M. L. Moore, G. Stange, D. Markovich, J. Biber, X. Testar, A. Zorzano, M. Palacin, and H. Murer. 1992. Expression-cloning of a cDNA from rabbit kidney cortex that induces a single transport system for cystine, dibasic, and neutral amino acids. Proc. Natl. Acad. Sci. USA. 89:5601-5605.

4. Bertran, J., S. Magagnin, A. Werner, D. Markovich, J. Biber, X. Testar, A. Zorzano, L. C. Kuhn, M. Palacin, and H. Murer. 1992. Stimulation of system $\mathrm{y}^{+}$-like amino acid transport by the heavy chain of human 4F2 surface antigen in Xenopus laevis oocytes. Proc. Natl. Acad. Sci. USA. 89:5606-5610.
5. Wells, R. G., W.-S. Lee, Y. Kanai, J. M. Leiden, and M. A. Hediger. 1992. The 4F2 antigen heavy chain induces uptake of neutral and dibasic amino acids in xenopus oocytes. J. Biol. Chem. 267:15285-15288.

6. Segal, S., and S. O. Thier. 1989. Cystinuria. In The Metabolic Basis of Inherited Disease. C. R. Scriver, A. L. Beaudet, W. S. Sly, and D. Valle, editors. McGraw-Hill, New York. 2479-2496.

7. Bergeron, M., and C. R. Scriver. 1992. Pathophysiology of renal hyperaminoacidurias and glucosuria. In The kidney: Physiology and pathophysiology. D. W. Seldin and G. Giebisch, editors. Raven Press, New York. 2947-2969.

8. Bell, G. I., N. M. Fong, M. M. Stempien, M. A. Wormstead, D. Caput, L. L. Ku, M. S. Urdea, L. B. Rall, and R. Sanchez-Pescador. 1986. Human epidermal growth factor precursor: cDNA sequence, expression in vitro and gene organization. Nucleic Acids Res. 14:8427-8446.

9. Devereux, J., P. Haeberli, and O. Smithies. 1984. A comprehensive set of sequence analysis programs for the VAX. Nucleic Acids Res. 12:387-391.

10. Krieg, P. A., and D. A. Melton. 1984. Functional messenger RNAs are produced by SP6 in vitro transcription of cloned cDNAs. Nucleic Acids Res. 12:7057-7070.

11. Hediger, M. A., M. J. Coady, T. S. Ikeda, and E. M. Wright. 1987. Expression cloning and cDNA sequencing of the $\mathrm{Na}^{+}$/glucose co-transporter. Nature (Lond). 330:379-381.

12. Hediger, M. A., M. L. Budarf, B. S. Emanuel, T. K. Mohandas, and E. M. Wright. 1989. Assignment of the human intestinal $\mathrm{Na}^{+} /$glucose cotransporter gene (SGLT1) to the q11.2 $\rightarrow$ qter region of chromosome 22. Genomics. 4:297300 .

13. Mohandas, T., T. Heinzmann, R. S. Sparkes, J. Wasmuth, P. Edwards, and A. J. Lusis. 1986. Assignment of human 3-hydroxy-3-methylglutaryl coenzyme A reductase gene to $\mathrm{q} 13 \rightarrow \mathrm{q} 23$ region of chromosome 5. Somat. Cell Mol. Genet. 12:89-94.

14. Kim, J. W., E. I. Closs, L. M. Albritton, and J. M. Cunningham. 1991. Transport of cationic amino acids by the mouse ecotropic retrovirus receptor. Nature (Lond). 352:725-728.

15. Pacholczyk, T., R. D. Blakely, and S. G. Amara. 1991. Expression cloning of a cocaine- and antidepressant-sensitive human noradrenaline transporter. $\mathrm{Na}$ ture (Lond). 350:350-354.

16. Guastella, J., H. Nelson, H. Nelson, L. Czyzyk, S. Keynan, M. C. Miedel, N. Davidson, H. A. Lester, and B. I. Kanner. 1990. Cloning and expression of a rat brain GABA transporter. Science (Wash DC). 249:1303-1306.

17. Buisson, G., E. Duee, R. Haser, and F. Payan. 1987. Three dimensional structure of porcine pancreatic $\alpha$-amylase at $2.9 \AA$ resolution. Role of calcium in structure and activity. EMBO (Eur. Mol. Biol. Organ.) J. 6:3909-3016.

18. Kanai, Y., M. G. Stelzner, W.-S. Lee, R. G. Wells, D. Brown, and M. A. Hediger. 1992. Expression of mRNA (D2) encoding a protein involved in amino acid transport in the S3 proximal tubule. Am. J. Physiol. 263:F1087-F1093.

19. Schafer, J. A., and M. L. Watkins. 1984. Transport of L-cystine in isolated perfused proximal straight tubules. Pfluegers Arch. Eur. J. Physiol. 401:143-151.

20. Voelkl, H., and S. Silbernagl. 1982. Mutual inhibition of L-cystine/L-cysteine and other neutral amino acids during tubular reabsorption. Pfluegers Arch. Eur. J. Physiol. 359:190-195.

21. Segal, S., P. D. McNamara, and L. M. Pepe. 1977. Transport interaction of cystine and dibasic amino acids in renal brush border vesicles. Science (Wash. DC). 197:169-170.

22. Biber, J., G. Stange, B. Steiger, and H. Murer. 1983. Transport of L-cystine by rat renal brush border membrane vesicles. Pfluegers Arch. Eur. J. Physiol. 396:335-341.

23. Taylor, A. K., I. Klisak, T. Mohandas, R. S. Sparkes, C. Li, R. Gaynor, and A. J. Lusis. 1990. Assignment of the human gene for CREB1 to chromosome 2 q32.3 $\rightarrow$ q34. Genomics. 7:416-421. 